\title{
PARA UNA ARQUEOLOGÍA DEL TESTIMONIO: EL ROL DE LA IGLESIA CATÓLICA EN UNA PRODUCCIÓN TEXTUAL (1973-1991)
}

\author{
POR
}

\author{
Ximena A. Moors \\ University of Florida
}

Durante la década de los setenta la publicación, circulación y recepción de obras testimoniales chilenas se realizó, simultáneamente, en espacios protegidos, a salvo de las represalias del censor, tales como el exilio y la clandestinidad. En el primero proliferaron testimonios que se convirtieron rápidamente en clásicos del género, ${ }^{1}$ contratextos de la historia oficial, que denunciaban al mundo los horrores de la dictadura militar. En el segundo, el testimonio circuló a escondidas, entre un público lector solidario pero reducido, sin constituir tampoco un reto al censor porque de tan secreto pasaba desapercibido para la mayoría de la población, eliminando así su intención esencial, esto es, propagar las malas nuevas. $^{2}$

Sin embargo, a partir de 1976, bajo estado de sitio y con una censura estricta sobre los medios de comunicación ${ }^{3}$ la Iglesia Católica chilena ya había establecido un tercer espacio

\footnotetext{
${ }^{1}$ Existe una abundante bibliografía sobre el tema. Puede consultarse, por ejemplo, Jorge Narváez, "El testimonio 1972-1982: Transformaciones en el sistema literario", en Testimonio y literatura, eds. René Jara y Hernán Vidal (Minneapolis: Institute for the Study of Ideologies and Literature, 1986): 252-255; Jaime Concha, "Testimonios de la lucha antifascista", Araucaria de Chile 4 (1978), 142-146; Manuel Jofré, "Literatura chilena de testimonio", Casa de las Américas (noviembrediciembre 1981), 150-156; y "Literatura en exilio", Cauce 17-30 (enero 1984), 24.

${ }^{2}$ Para una breve lista de escritos y publicaciones de circulación clandestina véase Ariel Dorfman, "Pequeñas alamedas: la lucha de la cultura chilena actual", Casa de las Américas (julio-agosto 1979), 62-64; y Jorge Narváez, op. cit. 62-64.

${ }^{3}$ El estado de la censura en 1976 se enmarca dentro de lo que algunos autores denominan la "primera etapa", que abarca desde 1973 hasta 1980. Desde 1973 hasta 1978 se implanta el Estado de Sitio, y es el período de despidos masivos, listas negras, fusilamientos, y cierre o reducción de las escuelas de periodismo, además de otras cátedras. Una censura estricta en los medios de comunicación genera una autocensura en periodistas y escritores así como en entrevistados y lectores. Véase Lidia Baltra Montaner, "Democracia=libertad de expresión; autoritarismo=censura", Mensaje (agosto 1985), 290-294. Consúltese también Jorge Edwards, "Chile: la lucha contra la censura", Vuelta 84 (1983), 54-57; y "El libro, ese objeto peligroso", Cauce (31 enero-15 febrero 1984), 24-26.
} 
al iniciar, abiertamente, un catastro testimonial a través de la Vicaría de la Solidaridad, organismo que recogió los testimonios de todas las víctimas de la violencia militar que se acogieron a su amparo. ${ }^{4}$ Su difusión se realizó a través de vías diversas, a saber: los archivos mismos, materialmente abiertos al público lector en las oficinas de la Vicaría; el boletín Solidaridad, publicación quincenal de la Vicaria; ${ }^{5}$ Mensaje, la revista del Arzobispado de Santiago; ${ }^{6}$ Análisis, ${ }^{7}$ revista de la Academia de Humanismo Cristiano,

${ }^{4}$ El primero de enero de 1976 el Cardenal Raúl Silva Henríquez firmó el decreto que creaba la Vicaría de la Solidaridad. Véase al respecto Vicaría de la Solidaridad: historia de su trabajo social (Santiago: Ediciones Paulinas, 1991), 54. Véase también Eugenio Ahumada et al, Chile, la memoria prohibida 2 (Santiago: Pehuén Editores, 1989), 197-212.

s "The vicariate's functions have included publishing the newspaper Solidaridad, which documents statistics on malnutrition, unemployment, and those who have disappeared or been arrested. With a circulation of about 33.000 , this biweekly newspaper is distributed among parishes, base communities, and social action groups throughout Chile". Véase Virginia Marie Bouvier, Alliance or Compliance: Implications of the Chilean Experience for the Catholic Church in Latin America, Latin American Series 3 (New York: Syracuse University, 1983), 64. Véase también Jorge Narváez, quien señala que tanto en el artículo "Editorial" del Vicario Cristián Precht, publicado en el primer ejemplar del boletín Solidaridad del mes de mayo de 1976, como en los relatos testimoniales subsiguientes del mismo boletín, "se puede encontrar en ciernes el desarrollo posterior del género [testimonial] en el interior del pais" (258).

${ }^{6}$ Mensaje, publicación mensual del Arzobispado de Santiago fundada en 1952, fue, entre las revistas disidentes, la más antigua y la de menor circulación. Expresa la ideología progresista de la Iglesia Católica chilena y, a pesar de su posición contraria a la dictadura, nunca fue requisada ni clausurada, aunque más de una vez el gobierno de Pinochet entabló querellas en contra de su director. Para mayor información sobre esta revista véase Brian Smith, The Church and Politics in Chile (Princeton: Princeton University Press, 1982), 135, 141, 189, 193-194, 202, 204, 315-316 y 320. Consúltese también Luis Torres, "Revistas periodísticas: estrategias de comunicación y coyuntura", Investigación sobre la prensa en Chile (1974-1984), compiladores Fernando Reyes Matta, Carlos Ruiz, Guillermo Sunkel (Santiago: Editorial Badel, 1986), 163-164 y 168-169.

${ }^{7}$ Análisis empezó a editarse en 1977, "bajo el patrocinio de la Academia de Humanismo Cristiano (organismo dependiente del Arzobispado de Santiago)" de la cual tuvo que independizarse en 1983 a raíz del nombramiento del señor Francisco Fresno como arzobispo. Véase Marcelo Mendoza, "Cuentos de cortes y recortes", Apsi (15-28 diciembre 1986), 14; y "No 100", Editorial, Análisis (23-30 julio 1985), 3. Revista quincenal, señalada como una de "las publicaciones de mayor relevancia en el ámbito periodístico nacional" (Torres 152) y "durante varios años la única revista disidente en Chile" llegó a ser "a fines de la década del setenta ... la más radicalizada de las revistas de oposición", motivo por el cual "las grandes empresas simplemente se negaron a imprimirla". Durante los tres primeros años su distribución se realizó precariamente "con una red compuesta de amigos y esposas del equipo editorial, usando sus propios autos para distribuir los ejemplares en Santiago", y la distribución a nivel nacional se inició en 1981, "llegando a todas las ciudades importantes", con una circulación de " 25.000 a 30.000 ejemplares". Circuló también en el extranjero, constituyendo uno de los tantos puentes entre Chile y sus exiliados que la leyeron "con entusiasmo". Véase Raquel Salinas, "La autonomía de la prensa: una ilusión", Investigación sobre la prensa en Chile (19741984) 238,243 . Véase también la declaración de propósitos de la revista en la página 1 de su primer ejemplar del mes de diciembre de 1977. 
dependiente del Arzobispado de Santiago ${ }^{8}$ los tribunales de justicia y la prensa disidente. Por la vía judicial se convirtieron, en su mayor parte, en fojas procesales de juicios malogrados, algunos de los cuales fueron reproducidos o transformados, por obra y gracia de abogados y periodistas comprometidos, en los libros-reportajes ${ }^{9}$ de los ochenta, en una ola creciente ${ }^{10}$ que culmina, en 1991, con la publicación del Informe de la Comisión de Verdad y Reconciliación o Informe Rettig, investigación patrocinada por el nuevo gobierno democrático que recoge y difunde, oficial y masivamente, además de otros, los mismos testimonios que la Vicaría había recibido y difundido más de una década atrás.

Durante los ochenta, mientras los testimonios iniciados en la Vicaría se hacen ambulatorios y se constituyen en textos productores de otras variantes discursivas (obras de teatro, videos alternativos, libros-reportajes, arpilleras, poesía), aquéllos publicados en el exilio también comienzan a movilizarse, entrando en el país a mediados de la década y,

\footnotetext{
${ }^{8}$ La Academia de Humanismo Cristiano fue creada en 1975 "como una manera de acoger a los académicos expulsados de las universidades, a partir de una iniciativa del Cardenal Raúl Silva. Fundada en base a un grupo de intelectuales de centro-izquierda, se ha transformado en uno de los principales centros de investigación científica del país en el área de las ciencias sociales". Véase Aldo Meneses C., El poder del discurso. La Iglesia Católica Chilena y el Gobierno Militar: 19731984 (Santiago: ILADES-CISOC, 1989), 174. Véase también Brian Smith, 322; y Eugenio Ahumada et al, 2, 228.

${ }^{9}$ El estudio y análisis del libro-reportaje como una modalidad específica dentro de la narrativa documental de la época aparece escasamente dentro de la recepción de obras testimoniales. Bernardo Subercaseaux destaca "la fuerte presencia del libro-reportaje" y observa que "han sido fundamentalmente periodistas mujeres las que se han atrevido a incursionar en esta modalidad", en "Testimonio: una modalidad genérica de nuestro tiempo", Pluma y Pincel (febrero 1987), 48. Véase también Alfonso Calderón, "Mesa Redonda: libro-reportaje, una opción del periodismo", en La invención de la memoria, Jorge Narváez (Santiago: Pehuén, 1988), 91-115; y Jorge Narváez, que atribuye al artículo precedente "el valor de una poética del género" (prólogo: 7).

${ }^{10}$ Esta ola creciente se manifiesta en dos niveles. Desde el punto de vista del mercado, los libros testimoniales o que se autoproclaman como tales encabezan las listas de "los libros más vendidos" y algunos de ellos se convierten en bestsellers. Véase al respecto "Los libros más vendidos", Cauce (17-30 enero 1984), 28; Claudia Dreifus, "Chile's Challenge", Mother Jones (September-October 1990), 27; y Jaime Blume S, “1989 y sus libros”, Mensaje (enero-febrero 1990), 42. Por otra parte, desde el punto de vista del sujeto, se revela una apertura progresiva que promueve los testimonios de seres secularmente victimizados y marginales, entre los cuales figuran principalmente las mujeres y los indígenas, a los que se suman cesantes, homosexuales travestis, bailarinas topless, etc. Véase al respecto Alfonso Calderón, "La voz de los cesantes", Apsi (14-27 julio 1986), 50; Joseph Ramos, reseña de $A$ medio morir cantando de David Benavente en Mensaje (agosto 1986): 317-318; "La manzana de Adán", Apsi (23-29 octubre 1989), 25-28; la reseña de La manzana de Adán de Claudia Donoso y Paz Errázuriz, Hoy (12-18 noviembre 1990), s/n; Carlos Piñera, "El suicidio de la reina del topless", Apsi (23 septiembre-6 octubre 1985), 34-39.
} 
a fines de los ochenta, circulan tanto los primeros como los segundos en la compañía, de dudoso género, ${ }^{11}$ de los testimonios de los vencedores. ${ }^{12}$

La denuncia de los crímenes de lesa humanidad, es decir, de las acciones y omisiones que constituyen una violación de los derechos humanos, y el apoyo moral a aquéllos que se embarcaron en la misma empresa ${ }^{13}$ se propagaron en un discurso testimonial dentro del marco doctrinario de Medellín y Puebla, ${ }^{14}$ en virtud del cual la Iglesia Católica chilena se propuso como meta la reconciliación nacional. Dicho objetivo se cumpliría una vez que la verdad fuera reconocida y que la justicia se restableciera, secuencia indispensable para el objetivo final: "mientras ello no ocurra [el establecimiento de la verdad] y mientras no se

\begin{abstract}
11 John Beverley señala que el testimonio "no es necesariamente la forma canónica de la narrativa de una sociedad socialista" y puede, en consecuencia, exhibir una articulación anti-socialista "como en los casos de las memorias carcelarias de Solzhenitsyn o Valladares". Sin embargo, el mismo autor postula que el testimonio "siempre delata, aunque sea tácitamente, la necesidad de cambio social estructural". Véase John Beverley, "Anatomía del testimonio", Revista de critica literaria latinoamericana 13/25 (1987), 14-15. Por otra parte, Narváez señala que estos textos pro-dictadura "no constituyen testimonios sino textos propagandísticos" (270), mientras Beverley pareciera no identificar el testimonio y la propaganda en términos excluyentes al calificar "el testimonio guerrillero ... como forma de propaganda de la vía armada" (10). Dentro de la crítica especializada dichos textos son ignorados y sólo se mencionan, de paso y ocasionalmente, para negarles su carácter testimonial. Véase al respecto Ana Houskova en "La narrativa chilena de resistencia antifascista", Revista de critica literaria latinoamericana $3 / 5$ (1977), 35.

${ }^{12}$ Por ejemplo, en 1989, Los zarpazos del puma de Patricia Verdugo y Ego Sum, Pinochet de las periodistas Raquel Correa y Elizabeth Subercaseaux "parecen encabezar las preferencias" y se consignan como "favoritos en librerías". Véase María Teresa Maluenda, "Princesas de ayer y pumas de hoy", Hoy (25-31 diciembre 1989), 28, 30.
\end{abstract}

${ }^{13}$ Este apoyo moral, en el campo testimonial, se expresa en cartas de presentación y prólogos a otros libros testimoniales así como sus correspondientes reseñas en la revista Mensaje. Como ejemplos se pueden mencionar las cartas de introducción o presentación del Cardenal Raúl Silva Henríquez a los libros-reportaje Miedo en Chile, de Patricia Politzer y Chile, la memoria prohibida, de Eugenio Ahumada et al. El Cardenal también escribe el prólogo de Recuerdos, de Anita Fresno (Santiago: CESOC, Ediciones Chile y América, 1985) que es presentado al público por el Vicario Precht. Véase "Recuerdos de Anita Fresno", Análisis (14-20 enero 1986), 23. El Vicario Precht también prologa el libro-reportaje de Patricia Verdugo André de La Victoria (Santiago: Editorial Aconcagua, 1985) y Expulsión (1986), de Eugenio Velasco. Véase Análisis (26 agosto-1 septiembre 1986), 30. El sacerdote-obrero José Aldunate L. prologa los libros testimoniales Nunca más, Chile, de la periodista Myriam Pinto (Santiago: Ediciones Terranova, 1986); Memorias contra el olvido de Hugo Villela, recopilador (Santiago: Amerinda Ediciones, 1987) y La dictadura me arrebató cinco hijos, de Otilia Vargas (Santiago: Mosquito Editores, 1991). En la revista Mensaje se publican, entre otras, las siguientes reseñas: de Julio Stragier, S.J. la reseña de Rodrigo y Carmen Gloria: quemados vivos de la periodista Patricia Verdugo (enero-febrero 1987): 57; de Javier García S.J. la reseña de Tortura: Documento de denuncia, editado por el Comité de Defensa de los Derechos del Pueblo (octubre 1987), 459-460; de José Aldunate la reseña de Memorias contra el olvido, (octubre 1987), 459; la reseña de José Carrasco. Asesinato de un periodista de las periodistas Patricia Collyer y María José Luque (agosto 1987), 347; y la reseña de Escuché sus gritos ... de Jesús Herreros (septiembre 1991), 360.

${ }^{14}$ Véase al respecto Enrique Correa y José Antonio Viera-Gallo, Iglesia y dictadura (Santiago: CESOC, Ediciones Chile y América, 1986). Véase también Enrique Dussel, De Medellín a Puebla una década de sangre y esperanza (1968-1979) (México: Centro de Estudios Ecuménicos, 1979). 
haga justicia, no podrá existir una verdadera pacificación en nuestra patria" (Sánchez 4: 790). Es en ese contexto que se desarrolla el quehacer testimonial de la Iglesia Católica durante la dictadura y es a la misma luz que hay que entender la continuidad de esa labor bajo la democracia.

La participación de la Iglesia Católica en el proceso testimonial se extendió, también en cumplimiento del mandato de Puebla, a la evangelización de la cultura, en una búsqueda de las señas de identidad nacional que se había iniciado bajo el gobierno del presidente Salvador Allende:

No cabe duda de que este proceso de dignificación tuvo una de sus manifestaciones más claras en los testimonios mismos que surgieron durante la Unidad Popular, diversificándose en distintos experimentos en universidades, asentamientos, industrias, poblaciones, etc., y cuya materialización unívoca fue la colección que publicó la Editorial Quimantú, "Nosotros los Chilenos", que se zambulló en las distintas facetas y actividades del subsuelo invisible del pueblo, mezclando seres tan peregrinos como los organilleros con rostros tan indiscutibles de nuestro horizonte como los mineros del carbón. (Dorfman, "Código político" 173)

Este proceso, interrumpido por el Golpe Militar, fue reasumido por la Iglesia Católica que auspició, además de otras manifestaciones de la cultura popular, ${ }^{15}$ el "rescate de la memoria histórica de los sectores populares" (Subercaseaux 49) a través de la gestación de las "historias de vida", construidas preferentemente con los testimonios de indígenas, mujeres pobladoras, campesinas y campesinos. ${ }^{16}$

${ }^{15}$ El Equipo de Educación Popular de la Vicaría (EDUPO), además de sus funciones de elaboración de "documentos de trabajo" coordina y organiza jornadas culturales tales como el Festival de la Expresión Joven en una estrecha convivencia de plástica, artesanía, música y teatro, y la mayoría de los grupos cultores de lo popular "se cobijan bajo el alero de las iglesias", amén de sindicatos, peñas y talleres. Véase Eliana Jara Donoso, "Creatividad popular: las cosas por su nombre ...", Apsi (20 julio-2 agosto 1982), 21-22. En cuanto a las arpilleras, "a partir del año 74, las arpilleristas comienzan a organizarse en talleres auspiciados por la Vicaría de la Solidaridad ... en talleres de hasta veinte mujeres que funcionan frecuentemente bajo la protección de la Vicaría de la Solidaridad". Véase, respectivamente, Marjorie Agosín, "Agujas que hablan: las arpilleristas chilenas", Fem (abril-mayo 1986), 19; y Eliana Moya Raggio, "Las arpilleras: cultura chilena de la resistencia", Literatura chilena: creación y crítica (julio-septiembre 1982), 3. En el campo de la música "la Iglesia Católica abría sus puertas a la solidaridad entregando espacios donde forjar la fraternidad y ensayar el derecho a expresarse. Los templos y centros parroquiales se comenzaban a llenar de sonidos y hombres para que aflorara el canto de siempre" y proporcionaban "valiosas instancias para la creación juvenil, a través de los festivales Una canción para Jesús y del sello Alpec". Véase Álvaro Godoy, "Canto que ha sido valiente siempre será canción nueva", La Bicicleta (abril-mayo 1981), 3, 13. En cuanto al teatro "hacia 1978 ya existen numerosos grupos ... constituidos por jóvenes estudiantes, cesantes, trabajadores y dueñas de casa, quienes reunidos inicialmente en torno a un soporte de la Iglesia Católica comienzan a hacer representaciones y divulgar 'teatralmente' problemas contingentes a sus respectivas comunidades". Véase Diego Muñoz, "Teatro poblacional chileno: 1978-1985. Antología crítica" (Disertación, Universidad de Minnesota, 1987), 1, 97-98.

${ }^{16}$ En la operación-rescate de la cultura popular participaron activamente numerosos organismos, entre los cuales se destacan CENECA, FLACSO, Centro Cultural Mapocho y el Centro de Estudios 
Si bien es cierto que estos testimonios no representaron en ningún momento un desafío a la censura, constituyeron, en cambio, una afirmación de identidad frente a un sistema económico que fomentaba tanto el desarrollo de una cultura elitista como la difusión y glorificación de una cultura de masas, ${ }^{17}$ ambas acríticas, alienadas y alienantes respecto de la situación histórica contingente:

Chile se convirtió en el país de libros más caros y de alcoholes importados más baratos del mundo. Salimos del circuito del conocimiento contemporáneo, pero ingresamos a la cultura de los spots publicitarios multinacionales y de las teleseries mexicanas. (Edwards, "Chile: la lucha" 55)

En el mismo espíritu de negación la Declaración de Principios del Gobierno de Chile, publicada el 11 de marzo de 1974, afirmaba: "En la familia la mujer se realza en toda la grandeza de su misión, que la convierte en la roca espiritual de la Patria", ${ }^{18}$ mientras entre los lemas gobiernistas desplegados a lo largo del país se leía: "En Chile no hay indios: sólo hay chilenos" (Galeano 45$)$.

\section{Los Desaparecidos}

Apenas terminado el golpe militar que derrocó el gobierno del presidente Salvador Allende, la Iglesia Católica expresó su preocupación por la situación de los vencidos, y “a

de la Mujer. Aquellos dependientes de la Iglesia Católica que mantienen una actividad testimonial constante y fecunda en la elaboración de "historias de vida" a lo largo de la década de los ochenta, comprometidos especialmente con las historias de vida de mujeres e indígenas, son la Academia de Humanismo Cristiano, la Vicaría Pastoral Obrera y la Vicaría Pastoral Campesina. Véase, a manera de ejemplo, "La mujer campesina", Apsi (28 septiembre-11 octubre 1989), 25-28; "Y asi fue creciendo", Apsi (15-28 noviembre 1983), 46; reseña de Martín Painemal Huenchal, vida de un dirigente mapuche, de Rolf Foerster, Apsi (13-26 diciembre 1983), 21; y otra de Carlos Ossandón B., Araucaria 27 (1984), 214-215; “Testimonios de lo nuestro", Apsi (18-31 octubre 1983), 44.

${ }^{17}$ Esta cultura elitista se cultiva gracias a los afanes del "mecenazgo privado", término acuñado por la revista Qué Pasa, (según reseña de la revista Andrés Bello en Araucaria 4 (1978), 224-225, llamado también "civismo de empresa", que surge basado en el "libre mercado" y en la aplicación del "principio de subsidariedad" y que presta su apoyo financiero preferentemente a "la plástica, la música de concierto y la lírica". Véase Soledad Bianchi, "El movimiento artístico chileno en el conflicto político actual", Casa de las Américas (enero-febrero 1982), 149. En cuanto a la cultura de masas, la televisión desempeña un papel preponderante en su difusión y en el fomento de una actitud consumista que excluye los libros, sobre los cuales se imponen fuertes impuestos. Además, se suprimen o reducen centros de enseñanza destinados a la reflexión crítica, a "la peligrosa novedad de discurrir". Véase Alfonso Calderón, "La cultura en Chile: las ventajas de la mala fe", Araucaria 24 (1983), 69; Ana María Foxley, “¿Qué cultura consumen los chilenos?”, Hoy (4-10 abril 1988), 41-42; y José Joaquín Brunner, "Mercado y cultura autoritaria", La Bicicleta (julio-agosto 1980), 45-47.

${ }^{18}$ Citado por Juan Jorge Faúndez, "Una roca dinamitada”, reseña de Mujeres de la ciudad, de Teresa Marshall et al, Cauce (2-8 octubre 1984), 58-60. En este libro se confrontan estos principios con la realidad del país a través de historias de vida en doce episodios. Sus gestoras sostienen que la mujer pobladora ha pagado uno de los costos más altos del régimen, el cual se refleja, entre otros males, en el aumento de la prostitución. 
partir del mes de septiembre de 1973, emitió una serie de declaraciones y documentos que reflejaron su posición de búsqueda de caminos de encuentro entre los chilenos y de la real necesidad de respetar los derechos humanos", pidiendo a los vencedores que se abstuvieran de "represalias innecesarias" (Informe de la Comisión 443). La creación, en virtud de un decreto arzobispal del mismo año, del Comité Pro-Paz, ${ }^{19}$ un organismo ecuménico destinado a proveer de asistencia jurídica, técnica, económica y espiritual a los perseguidos por el nuevo régimen fue la única acción efectiva que se inició para contrarrestar el cuadro de violaciones a los derechos humanos que se estaba produciendo. A fines de 1975 el Comité Pro-Paz se disuelve por orden del general Augusto Pinochet y el Arzobispo crea inmediatamente la Vicaría de la Solidaridad, organismo que continúa las funciones de socorro y amparo, mientras se embarca en una lucha frontal contra un poder judicial complaciente con una Junta de Gobierno todopoderosa. En este trance, la Iglesia abrió sus puertas, a través de la Vicaría, a las víctimas de la brutalidad militar para que ellos y ellas depusieran sus testimonios por escrito y los hicieran valer luego, asistidos legalmente, ante los tribunales de justicia, siendo los casos de los detenidos-desaparecidos la columna vertebral de dichos testimonios. ${ }^{20}$ En noviembre de 1978, al comprender la Vicaría que la interposición de todos los mecanismos legales disponibles tales como el recurso de amparo (habeas corpus), la denuncia y la querella criminal por los delitos de secuestro y de arresto ilegal "no han dado ningún resultado" (Precht, Introducción, ¿Dónde están? 1: 7) así como también del fracaso de las instancias administrativas y de la interpelación directa de los obispos a las autoridades pertinentes, decide sacar a la luz del mundo secular una selección de fichas de personas desaparecidas con los correspondientes testimonios de amigos y familiares y acciones legales y administrativas interpuestas, bajo el título ¿Dónde están?, con la intención expresa de reiterar la situación a la autoridad competente y denunciarla al público lector. Hasta entonces estos testimonios habían estado confinados al círculo restringido de los archivos de la Vicaría, a fojas procesales, y a la circulación limitada del boletín Solidaridad; y aunque tanto el acceso a los archivos como a los expedientes, en tanto terminados, estaba abierto al público, pocos eran los lectores que acudían a esas fuentes, ya por ignorancia, ya por miedo, a menos que estuvieran directamente involucrados como víctimas, defensores o miembros del poder judicial.

El lenguaje frugal de los testimonios presentados en ¿Dónde están? contrasta con el discurso apasionado de los prólogos que los preceden. En ellos, se repite la aspiración de la Iglesia a una reconciliación nacional en un llamado directo al público lector. Es así que en la introducción al primer volumen del mes de noviembre de 1978 el Vicario Cristián

\footnotetext{
${ }^{19}$ Para mayor información sobre el Comité Pro Paz véase Jaime Escobar M, Persecución a la Iglesia en Chile (Martirologio 1973-1986) (Santiago: Terranova Editores, 1986), 53-54; Aldo Meneses C, El poder del discurso, (Santiago: ILADES-CISOC, 1989), 173; Informe Rettig (Santiago: Ediciones del Ornitorrinco, 1991), 444. Véase también Eugenio Ahumada et al, en Chile, la memoria prohibida 1 y 2 (Santiago: Pehuén Editores, 1989), 375-388; 23-63, 167-195.

${ }^{20}$ Entre 1978 y 1980 el departamento jurídico de la Vicaría había asistido legalmente a un número aproximado de 50000 chilenos. Véase al respecto Hugo Fruhling, Nonprofit Organizations as Opposition to Authoritarian Rule: The Case of Human Rights Organizations and Private Research Centers in Chile. PONPO Working Paper No 96 and ISPS Working Paper No 2096, Institution for Social and Policy Studies, Yale University 1985, 29.
} 
Precht señala que "los testimonios que entregamos a la consideración de la comunidad cristiana y de todos los hombres de conciencia recta" contribuirán a establecer "la verdad que libera" (11). Un segundo volumen sale a luz en febrero de 1979 seguido por un tercero, del mismo mes, en cuyo prólogo se califica la situación de los detenidosdesaparecidos como "una herida abierta en el flanco de Chile" (Hourton 3: 533). En el cuarto volumen, del mes de marzo, se reclama el derecho de los chilenos y de los familiares de los detenidos-desaparecidos "a conocer la verdad" y coincide con el descubrimiento reciente de los restos humanos de Lonquén (Sánchez 790). En el prólogo al volumen quinto, del mismo mes, se declara expresamente que "la Iglesia Católica no podía quedar muda e indiferente" ante la situación de los detenidos-desaparecidos y que "sólo en la Verdad podremos reconciliarnos" (Ferraris 942, 944). En el prólogo del volumen sexto, publicado en el mes de abril, se cita las palabras del Papa que reconoce en la defensa de los derechos humanos un "auténtico compromiso evangélico" (Ariztía 1197) y en el último volumen, del mes de mayo, a manera de prólogo se publica la homilía del Vicario Precht “¿Por quién llora la hija de mi pueblo?”, pronunciada en la misa celebrada por los “detenidosdesaparecidos" hallados en los hornos de las minas de Lonquén. Las únicas evidencias escritas de recepción y promoción comercial de estos textos dentro del país se encuentran en el boletín Solidaridad $;{ }^{21}$ y en un breve párrafo del prólogo a Detenidos-desaparecidos, publicado un año más tarde, se alude a ellos:

En el curso del año 1979, la Vicaría de la Solidaridad del Arzobispado de Santiago, entregó a la publicidad, una colección de siete tomos titulados ¿Dónde están? en que presentan -objetiva y escuetamente - los antecedentes que los obispos de diversas diócesis hicieron llegar al señor Ministro del Interior informando de los detalles y pruebas que obraban en su poder acerca de las personas desaparecidas, desde 1973 en adelante. (Verdugo 15)

En el mes de marzo de 1980 la Editorial Aconcagua ${ }^{22}$ publica dos libros, que representan la segunda salida al mundo de los testimonios de la Vicaría, con el propósito expreso de ponerlos "al alcance del público lector" (Verdugo, Detenidos 11). Se trata de Lonquén, ${ }^{23}$ del abogado y colaborador de la Vicaría de la Solidaridad Máximo Pacheco y Detenidos-desaparecidos: una herida abierta ${ }^{24}$ de los periodistas Patricia Verdugo y Claudio Orrego. En la introducción a Detenidos-desaparecidos, los periodistas advierten:

\footnotetext{
${ }^{21}$ Véase Solidaridad, segunda quincena, febrero, 1979, 9; y Solidaridad, primera quincena, abril 1980, 23.

${ }^{22}$ Claudio Orrego, ideólogo demócratacristiano y periodista, "en 1979, al frente de la Editorial Aconcagua ... dará curso a una línea de publicaciones de carácter testimonial, las cuales se hayan inscritas en el marco ideológico del postulado político de Orrego"; en Jorge Narváez, 258.

${ }^{23}$ El Lonquén de Pacheco había sido precedido por el poema testimonial "Lonquén", de Andrés Sabella, publicado en Análisis (octubre 1979), 34.

${ }^{24} \mathrm{El}$ caso Lonquén también se presenta en Detenidos-desaparecidos, bajo la forma de un capítulo titulado "Lonquén" (67-105).
} 
Todo el material utilizado es estrictamente objetivo y de carácter público. Él se encuentra recopilado en las numerosas y exhaustivas publicaciones de la Vicaría de la Solidaridad del Arzobispado de Santiago, fuentes periodisticas y archivos judiciales. Tras cada uno de los casos presentados - todos ellos por vía de ejemplo y no de relación acabadaaparecen numerosos antecedentes y documentos que han sido presentados ante los Tribunales de Justicia. Nuestro trabajo ha consistido en seleccionarlo, ordenarlo y resumirlo de manera de ponerlo al alcance del público lector. (11)

A pesar de ello, "la primera edición fue prohibida y circuló clandestinamente. Sólo en 1983 el libro pudo comenzar a llegar a destino" (Calderón, "Mesa Redonda" 104). A despecho de la prohibición, en una reseña anónima publicada ese mismo año en la revista Mensaje del mes de junio, se califica Detenidos-desaparecidos como "la obra" que "expone la realidad factual, jurídica y humana de los centenares de casos de detenidos por personal militar y policial ... 'desaparecidos"' (294). Lonquén, del abogado y ex-ministro de educación Máximo Pacheco Gómez, tuvo que acatar el decreto, emitido pocos días antes del fijado por la editorial Aconcagua para su distribución, que ordenaba que "todo libro debería pasar por la censura y conseguir autorización para circular". Se prohibió su venta y Pacheco presentó un recurso de apelación ante la Corte Suprema, "alegando que la medida era ilegal" (Piña 41), el cual fue rechazado "por unanimidad" ("En breve”). El texto:

contiene las piezas más importantes de la investigación realizada, a partir de diciembre de 1978, sobre el hallazgo de 15 cadáveres en un horno abandonado a unos 50 kilómetros de Santiago. Sólo la Introducción del texto - tres carillas- la escribió Pacheco. El resto es una reproducción exacta de lo más esencial del proceso, según copia fiel de los expedientes. Pacheco agregó, además, la información aparecida en los diarios, donde se decía que los carabineros implicados en la muerte de los hombres se acogían a la amnistía decretada por el gobierno. (Piña 41)

En la Introducción Pacheco señala:

El Vicario de la Solidaridad informó a los participantes que un sacerdote había recibido la denuncia de un particular sobre la "existencia de un cementerio de cadáveres en la localidad de Lonquén" .... Ignoraba el denunciante la forma y circunstancias en que había ocurrido la muerte de las personas enterradas. Este sacerdote, autorizado expresamente por su informante, había puesto los antecedentes en conocimiento de la autoridad eclesiástica. Ante la gravedad de los hechos denunciados, el señor Cardenal don Raúl Silva Henríquez había decidido formar una Comisión integrada por las personas que asistimos a la reunión, para que verificara la acusación. (7-8)

Una vez comprobada la veracidad de la denuncia, ${ }^{25}$ la misma Comisión hizo "una presentación al Presidente de la Excelentísima Corte Suprema, poniendo estos hechos en su conocimiento, a fin de que se adoptaran las medidas que aseguraran una rápida y

${ }^{25}$ Según otra versión, Lonquén no se originó en un testimonio sino en la confesión de uno de los victimarios ante un sacerdote, en noviembre de 1978. Véase León Gómez A., Que el pueblo juzgue: historia del golpe (Santiago: Terranova Editores, 1988), 178-179. 
exhaustiva investigación (9). Es así que Lonquén y Detenidos-desaparecidos comparten un mismo origen al iniciarse, como textos, en la Vicaría y por su intercesión, y la misma intención de sus gestores de poner al alcance fácil del público lector los hechos desnudos. En consecuencia, optan por la transcripción de documentos públicos que, en el caso de Lonquén, conforman casi todo el texto, recurso utilizado además para eludir la censura. Pacheco, segun confesión propia, se desistió de escribir un libro "al pensar que sería objetado por el gobierno por su trayectoria demócratacristiana y su carácter de disidente del gobierno militar" y, en cambio, "seleccionó ... parte del expediente de cinco tomos y 1850 fojas, entregándolo a la editorial Aconcagua", basado en que "un expediente terminado" y el de Lonquén lo estaba, "puede ser conocido por cualquier ciudadano". El abogado señala que "cualquier persona puede ir a los tribunales, según la ley, y solicitar los expedientes de un proceso. Son públicos. Por lo tanto éstos se pueden imprimir y distribuir" (Piña 41).

Jorge Narváez reconoce en Lonquén "una manifestación literaria del período" (263) mientras Bernardo Subercaseaux lo califica de "instrumento adecuado para hacer (aunque ficticiamente) justicia donde la Justicia no la hace", ubicándolo, junto a ¿Quién mató a Tucapel? (1987) del abogado Rodolfo Sesnic y Laberinto (1984) del fiscal norteamericano Eugene Propper y Taylor Branch en la categoría de obras "de marcado carácter documental, en que se interioriza a la opinión pública en los procesos judiciales y en que se busca que los hechos y los documentos hablen por sí solos" (49).

En 1984, Lonquén y Detenidos-desaparecidos que habían dejado de circular clandestinamente en 1983 (Edwards, "El libro" 24) figuran entre los libros más vendidos del año ("Los libros más vendidos") junto a La casa de los espiritus de Isabel Allende y Los generales del régimen y Los civiles del régimen, "serie de entrevistas a conspicuas figuras del autoritarismo" (Aguirre 23). En 1986 Lonquén ya llevaba once ediciones a su haber.

En 1984 se estrena No olvidar de Ignacio Agüero, que es Lonquén convertido en película, "después de dos años en manos de la censura", film que "asume, con notable rigor, su carácter testimonial" sobre "el hallazgo, en el interior de unos hornos, de 15 personas detenidas en 1973" (Román 46). En la revista La Bicicleta se consigna que el film "se rodó entre el 79 y el 82" entregándose un recuento detallado de su historia. Se señala que "las imágenes y testimonios de los familiares son impactantes" y que la crítica "ha reaccionado positivamente, destacando su realismo y autenticidad" (E.L. 40). En 1988, el caso de los asesinados en la mina de cal de Lonquén surge nuevamente en el capítulo 6 del libro de León Gómez A., Que el pueblo juzgue. La historia del golpe de estado, bajo el título "Los hornos de la muerte" (175-189). En el año 1989 el caso Lonquén reaparece en dos capítulos de Chile, la memoria prohibida, bajo los títulos "El gran miedo" (1: 213-219) y "El derecho a ser persona" (3: 145-158) y en 1990 surge otra vez en el libro-reportaje Tiempo de días claros: los desaparecidos de la periodista Patricia Verdugo, bajo la forma de un extenso capítulo titulado "Lonquén: un horno para quince" (151-208).

Lonquén y Detenidos-desaparecidos marcan el comienzo del viaje de los testimonios fuera del ámbito protector de la Iglesia y de su conversión en textos itinerantes bajo diversas formas discursivas. Los preferidos llegan a ser casos como el de Lonquén, resueltos en el hallazgo de los desaparecidos. A continuación, se intenta una relación parcial de aquéllos que durante los ochenta se repitieron con mayor frecuencia, en una jornada que culmina, pero no cesa, en el Informe Rettig. 
Antes de que el año 1984 se cierre con la implantación, por segunda vez, del Estado de Sitio, la revista Apsi alcanza a publicar una serie de testimonios, dos de los cuales acusan su origen en los archivos de la Vicaría: "Los secretos del patio 29" de Augusto Góngora y "La historia no contada de los fusilados que sobrevivieron", de la periodista Marcia Pineda. ${ }^{26}$ En 1990, el primero se convierte, bajo el título "Paine y su duelo oculto", en el primer capítulo del libro-reportaje Tiempo de días claros de la periodista Patricia Verdugo (13-38), y el segundo conforma uno de los catorce capítulos del libro-reportaje Miedo en Chile, de la periodista Patricia Politzer, que sale a luz en 1985, "gracias a una beca de la Academia de Humanismo Cristiano, el Consejo Latinoamericano de Ciencias Sociales y el World University Service" (Orellana 212). Entre otras reseñas, ${ }^{27}$ en un ejemplar de la revista Mensaje se señala:

Mas allá de esta experiencia humana enriquecedora de asomarse al abismo de otras existencias, aflora también en esta obra el drama de Chile o de los tantos Chile que cohabitan esta tierra y que no se atreven a comunicarse para intentar "una comunidad nacional". (Hevia 478)

En 1987 Retablo de Yumbel, de Isidora Aguirre, obra de teatro inspirada en el primer hallazgo de desaparecidos en el mes de octubre de 1979, gana el Premio Casa de las Américas. Sus antecedentes se remontan a los archivos de la Vicaría y se repiten en el volumen séptimo de ¿Dónde están?; en Yumbel, cuando los muertos vuelvan a su tierra, editado en 1983 por la Fundación de Ayuda Social de las Iglesias Cristianas; y en el capítulo séptimo de Tiempo de días claros: los desaparecidos titulado "A Los Angeles nunca llegaron ..." (209-236). En el año 1989 la revista Apsi anuncia el próximo lanzamiento de Chile, la memoria prohibida:

El libro-reportaje, publicado por Editorial Pehuén, fue escrito por Eugenio Ahumada, Rodrigo Atria, Javier Luis Egaña, Augusto Góngora, Carmen Quesney, Gustavo Saball y Gustavo Villalobos, casi todos, ligados a la creación y funcionamiento de la Vicaría de la Solidaridad. Entre sus capítulos, se encuentran la caída del gobierno de Allende, los entierros de Lonquén, la creación de la Dina, las muertes de Letelier y Prats, la fundación del Comité Pro Paz, el itinerario del Comando Conjunto, el caso Calama y el asesinato de Tucapel Jiménez. ("Diez años de memoria")

En una reseña de la revista Hoy se consigna que la obra está constituida por "tres tomos con casi 1.500 páginas" y es una "recopilación" de las violaciones de los derechos humanos entre 1973 y 1983 ("Recuento de una década trágica"). En la revista Pluma y Pincel se califica el texto de "obra fundamental" porque "recoge en sus tres gruesos tomos lo que bien podría considerarse la summa informativa esencial de esa década ominosa"

\footnotetext{
${ }^{26}$ En la revista Hoy también se publicó, en el verano de 1983, una serie de fascículos sobre los detenidos-desaparecidos, a cargo de las periodistas Marcela Otero y Carmen Ortúzar, pero no fue posible acceder a ellos.

${ }^{27}$ Véase también la reseña de Jaime Valdivieso de Miedo en Chile, Apsi (18 noviembre-l diciembre 1985), 52, y la de Carlos Orellana en Araucaria 32 (1985), 212-213.
} 
(De Santiago 74). En la Revista Chilena de Derechos Humanos, fundada en 1985 por la Academia de Humanismo Cristiano, ${ }^{28}$ se publica otra reseña que describe el texto como "el relato de un trozo de este país (junio de 1973 a mayo de 1983), desde la perspectiva de los derechos humanos" (108).

El primer volumen se inicia con una serie de textos de adhesión de "distinguidas personalidades ligadas a la defensa de los derechos humanos", dos de los cuales pertenecen al Vicario de la Solidaridad Cristián Precht Bañados y al Cardenal Raúl Silva Henríquez. "Sin memoria no hay identidad" (xvii) sostiene el primero, idea que los gestores repiten en el prólogo: "Aunque dolorosa, ésta es parte de nuestra identidad" (xxxii).

Los zarpazos del puma es el título del libro-reportaje que Patricia Verdugo publica, también, en 1989. En él se investiga el fusilamiento de " 72 prisioneros políticos ... sin juicio previo y obviando las sentencias que en algunos casos los consejos de guerra ya habían dictado" ("Los zarpazos del puma. Confesiones militares" 18). La historia se repite ese mismo año en el capítulo 14 de Chile, la memoria prohibida, bajo el título "El helicóptero de la muerte" (1: 341-373). Con antecedentes testimoniales desde la Vicaría, la historia ya había aparecido en 1988, en los capítulos 7, 8, 9, 10 y 11 del libro-reportaje de León Gómez A, Que el pueblo juzgue. Historia del golpe (235-272).

En 1990, el juez René García Villegas publica Pisagua! Caín: ¿Qué has hecho con tu hermano?, texto que iniciado en la Vicaría, se repite en varios otros como, por ejemplo, el capítulo 12 titulado "Pisagua, letra del dolor" (273-287) del libro de Gómez Araneda, Que el pueblo juzgue, y en Tumbas de cristal publicado en 1991, en el capítulo titulado "Pisagua. Como si hubieran muerto ayer" (15-120). Tiempo de días claros: los desaparecidos, de Patricia Verdugo, se publica en 1990 y es una reelaboración de su predecesor: Detenidos-desaparecidos: una herida abierta. La periodista señala en una nota introductoria:

No es la primera vez que escribo sobre detenidos de mi patria, que luego desaparecieron. En el invierno de 1979, mi amigo Claudio Orrego Vicuña me lo propuso y el resultado fue Una herida abierta, libro que debió circular clandestinamente, ya que no logró pasar las barreras de la censura militar que imperó hasta 1983. Hoy, con el peso de tantas evidencias que fueron surgiendo de las investigaciones judiciales y periodísticas, creo cumplir con mi deber al publicar este reportaje con materiales recopilados a lo largo de todos estos años. $(\mathrm{s} / \mathrm{n})$

El 25 de abril de 1990 se promulga el Decreto Supremo 355 que crea la Comisión de Verdad y Reconciliación, cuyo artículo primero ordena en su primer párrafo:

Créase una Comisión Nacional de Verdad y Reconciliación que tendrá como objeto contribuir al esclarecimiento global de la verdad sobre las más graves violaciones a los derechos humanos cometidas en los últimos años, sea en el país o en el extranjero, si estas últimas tienen relación con el Estado de Chile o con la vida política nacional, con el

${ }^{28}$ La fundación de la Revista Chilena de Derechos Humanos se consigna en Análisis (13-20 agosto 1985), 16-27. 
fin de colaborar a la reconciliación de todos los chilenos y sin perjuicio de los procedimientos judiciales a que puedan dar lugar tales hechos. (Informe de la Comisión VIII)

En virtud de este artículo los objetivos de la Comisión, tal como su nombre lo indica, se concentran en la búsqueda y establecimiento de la verdad por la verdad con fines de reconciliación nacional y en el artículo segundo se confirman tales limitaciones al privar expresamente a la Comisión de "funciones jurisdiccionales propias de los Tribunales de Justicia ni interferir en procesos pendientes ante ellos" (VIII). En el proceso inicial de recoger información "comenzó la labor de consultar los archivos de los organismos de derechos humanos, especialmente el de la Vicaría de la Solidaridad" (Informe Rettig 5).

En el mes de febrero de 1991 el gobierno publica los resultados de la investigación bajo el título Informe de la Comisión Nacional de Verdad y Reconciliación, el cual se transforma, en las ediciones realizadas por editoriales comerciales, en el Informe Rettig. El 4 de marzo del mismo año, el presidente Patricio Alwyn se dirigió al país por cadena nacional de televisión para informarle "que durante muchos años (los del régimen militar) se torturó, asesinó e hizo desaparecer a cientos de compatriotas". Se reconocía, "por primera vez, pública y oficialmente", lo que se había convertido, con los años, en un secreto a voces. La difusión del texto se realizó masivamente, "en los carros del metro y en los bancos de las plazas se podía observar a la gente leyendo el contenido del Informe" y "se calcula en 200.000 los suplementos de diarios como La Nación y La Época que se agotaron rápidamente en esos días". A ello se sumó la distribución del libro "entre autoridades e instituciones" (Rojas 20-23).

A pesar de la enorme difusión del Informe Rettig y del respaldo gubernamental con que contó, su eficacia como instrumento de justicia, según muchos, no satisfizo las expectativas de la mayoría de los chilenos. ${ }^{29}$ Tanto así que la Comisión Chilena de Derechos Humanos y el Centro Ideas comienzan "una campaña nacional de educación por la verdad y los derechos humanos" denominada Para creer en Chile, "que nace como iniciativa de la sociedad civil, para difundir masivamente los contenidos y propuestas del Informe Rettig" (Rojas 25). Entre sus participantes se cuenta la Vicaría de la Solidaridad que inicia por cuenta propia, y ese mismo año, la publicación de libros testimoniales. En esta nueva etapa la Vicaría contrata a Ruby Weitzel, periodista y escritora, encomendándole "la elaboración" de Tumbas de cristal, que sale a luz en agosto de 1991 y encargándole otro, "en preparación" (contratapa de Tumbas de cristal).

El título del libro, que trata del hallazgo de detenidos-desaparecidos en 1990, representa una respuesta al otorgado a la colección que la misma Vicaría había publicado doce años atrás, ¿Dónde están?, lo que se sugiere en el prólogo pero más claramente en la contratapa:

\footnotetext{
${ }^{29}$ Para mayor información sobre el desaliento que surge después de la publicación del Informe Rettig léase Andrés Domínguez V., "La Verdad ya comenzó, la Justicia espera, la Reconciliación ...", Mensaje (marzo-abril 1991), 57-58; Marcel Young Debeuf, “¿Qué pasa con los derechos humanos?", Mensaje (diciembre 1991), 505-506; Gloria Elgueta, "Informe Rettig: La justicia que no llega", Página abierta (22 julio-4 agosto 1991), 21.
} 
Durante años se los negó, se los ocultó y se intentó que jamás se les encontrara. Las fosas que los escondieron en sitios remotos y aislados guardaron como tumbas este secreto. Sin embargo, como si se hubiera tratado de tumbas tan transparentes y frágiles como el cristal, un día revelaron su secreto.

Tumbas de Cristal es un libro que se lee con el espanto de saber que lo narrado en verdad ocurrió, pero que despliega el atractivo de una novela de suspenso, de crimen, de misterio, de terror y de amor, hábilmente escrita por una profesional. Ya no es lectura para jueces y abogados ni para lectores de la prensa; y mucho menos la entrega escueta de testimonios desnudos. Se trata de la transformación de una serie de testimonios en "ficción":

Por debajo del polvo que por tanto tiempo la aprisionó, una mano blanca, de dedos largos, casi intacta, se deslizó fuera del saco como en una súplica. Pero si aquella mano conmocionó a los hombres, el resto, cuando quedó al descubierto, los estremeció. (21)

El hilo conductor es la búsqueda del paradero último de la persona amada, del padre, por ejemplo:

Lo primero y más nítido que vio Patricio fueron las manos blancas, de dedos largos y delgados. Denotaban que se trataba de un hombre muy joven. No era su padre. Ello lo tranquilizó un tanto. Sin embargo cuando observó la huella de las balas en el pecho, los ojos vendados y el gesto de dolor en un grito jamás escuchado, Patricio llegó de nuevo al borde del desgarro. Así también iban a encontrar a su padre, tarde o temprano, así lo iban a encontrar. (29)

O del hijo "entre las fosas abiertas":

¿Dónde estás, hijo ... dónde estás ...? Sólo los sollozos ahogados de otros tan abatidos como ese anciano y el viento del desierto respondieron al grito desgarrado que encerraba toda la desesperación por el hijo perdido. Porque Michel Nash no estaba entre los vivos. Tampoco estaba entre los muertos. (96)

Cabe preguntarse por las razones que movieron a la Vicaría a emprender esta nueva jornada testimonial. El Secretario Ejecutivo de la Vicaría, Alejandro González, señala que se trata de "subsanar" una "omisión" de la que adolecen ¿Dónde están? y el Informe Rettig, que no consignan "las dramáticas experiencias vividas por las propias víctimas" y "el sufrimiento y la angustia que aún se prolonga en su entorno social más próximo, especialmente sus mujeres, sus hijos, sus padres" (10). Es posible, sin embargo, sospechar que haya razones de fuerza mayor, ya que las aducidas por González, si bien son pertinentes en el contexto limitado de ¿Dónde están? y el Informe Rettig, no lo son tanto cuando se analizan a la luz de la profusa escritura testimonial de los ochenta que revela, en mayor o menor medida, el dolor de las víctimas sobrevivientes y de los familiares.

Ello obliga a una relectura, entre líneas, de la declaración de intenciones de la Vicaría, por la voz de González, y a remitirse a sus principios, los prólogos de ¿Dónde están?, para interpretar dichas intenciones cabalmente. ¿Dónde están? se publicó en el contexto de la 
verdad denegada sin la cual no era posible hacer justicia y, por ende, iniciar la reconciliación nacional.

Doce años más tarde la verdad de los desaparecidos se reconoce oficial y públicamente como una "verdad común" que merced al Informe Rettig es "ampliamente compartida por la sociedad chilena y no contradicha" (González 9), pero la justicia no se hace; para muchos, el Informe Rettig nació "muerto" (Rojas 24). Tumbas de cristal se publica entonces en el contexto de la justicia denegada, que hace imposible la reconciliación nacional, la cual, en los noventa, todavía constituye un asunto pendiente, una aspiración insatisfecha, una herida abierta.

\section{Obras Citadas}

Aguirre, Mariano. "El libro, casi una nostalgia". Cauce (6-12 noviembre 1984), 23-24. Ahumada, Eugenio, et al. Prólogo. Chile, la memoria prohibida. Santiago: Pehuén Editores, 1989, xxxi-xxxiii.

Ariztía, R., Gustavo. Prólogo. ¿Dónde están? 6. Por el Arzobispado de Santiago. Vicaría de la Solidaridad. Santiago: Vicaría de la Solidaridad, 1979, 1197-1198.

Calderón, Alfonso. "Mesa Redonda: libro-reportaje, una opción del periodismo". La invención de la memoria. Jorge Narváez. Santiago: Pehuén, 1988, 91-115.

Chile, la memoria prohibida. Reseña. Revista Chilena de Derechos Humanos. (agosto 1990), 108-109.

De Santiago, Carlos. "El rescate de la memoria histórica". Pluma y Pincel 7 (enerofebrero 1991), 72-75.

Patricia Verdugo y Claudio Orrego. Detenidos-desaparecidos: una herida abierta (Reseña). Mensaje (junio 1980), 294.

"Diez años de memoria" Apsi (9-15 octubre 1989).

¿Dónde están?, 7 volúmenes. Arzobispado de Santiago, Vicaría de la Solidaridad. Santiago: Arzobispado de Santiago, Vicaría de la Solidaridad, 1978-1979.

Dorfman, Ariel. "Código político y código literario: el género testimonio en Chile hoy". Testimonio y literatura. Eds. René Jara y Hernán Vidal. Minneapolis: Institute for the Studies of Ideologies and Literature, 1986.

Edwards, Jorge. "Chile: la lucha contra la censura". Vuelta 84 (1983), 54-57.

"En breve". Hoy (31 diciembre 1980-6 enero 1981), 9.

E. L. "Para impedir el olvido". La Bicicleta (20 junio 1985), 39-40.

Ferraris del C., R. P. Gustavo. Prólogo. ¿Dónde están? 5. Por el Arzobispado de Santiago. Vicaría de la Solidaridad. Santiago: Vicaría de la Solidaridad, 1979, 1197-1198.

Galeano, Eduardo. "La burbuja gris: los indios (I)". Análisis (7-13 noviembre 1988), 45. Góngora, Augusto. "Los secretos del patio 29". Apsi (10-16 abril 1984): 9-12.

González, P., Alejandro. Prólogo. Tumbas de cristal. Ruby Weitzel. Santiago: Ediciones ChileAmérica, CESOC, 1991, 9-11.

Hevia, Renato.S.J. Reseña de Miedo en Chile, de Patricia Politzer. Mensaje (noviembre 1985), 478.

Hourton, Jorge. Prólogo. ¿Dónde están? 3. Por el Arzobispado de Santiago. Vicaría de la Solidaridad. Santiago: Vicaría de la Solidaridad, 1979, 533-534. 
Informe de la Comisión de Verdad y Reconciliación, 3 volúmenes. Por la Comisión de Verdad y Reconciliación. Santiago: Secretaría de Comunicación y Cultura, 1991.

Informe Rettig, 2 volúmenes. Por la Comisión de Verdad y Reconciliación. Santiago: Ediciones del Ornitorrinco, 1991.

"Los libros más vendidos". Cauce (17-30 enero 1984), 28.

Narváez, Jorge. "El testimonio 1972-1982. Transformaciones en el sistema literario".

Testimonio y literatura. Eds. René Jara y Hernán Vidal. Minneapolis: Institute for the Studies of Ideologies and Literature, 1986, 235-279.

No olvidar, video documental. Director Ignacio Agüero. Reseña. Cauce (23-29 octubre 1984), 45.

Orellana, Carlos. Reseña de Miedo en Chile de Patricia Politzer. Araucaria 32 (1985), 212-213.

Pacheco, Máximo. Lonquén. Santiago: Editorial Aconcagua, 1980.

Pineda, Marcia. "La historia no contada de los fusilados que sobrevivieron", Apsi (29 octubre-11 noviembre 1984), 17-20.

Piña, Juan Andrés. "Lonquén 'pena"”. Hoy (14-20 enero 1981), 41.

Politzer, Patricia. Miedo en Chile. Santiago: Cesoc, Editorial Chile y América, 1985.

Precht Bañados, Cristián. "Sin memoria no hay identidad". Chile, la memoria prohibida

1. Por Eugenio Ahumada, et al. Santiago: Ediciones Pehuén, 1989, xvii.

Introducción. ¿Dónde están? 1. Por el Arzobispado de Santiago. Vicaría de la Solidaridad. Santiago: Vicaría de la Solidaridad, 1978, 5-11.

“¿Por quién llora la hija de mi pueblo?”. ¿Dónde están? 7. Por el Arzobispado de Santiago. Vicaría de la Solidaridad. Santiago: Vicaría de la Solidaridad, 1979, 1515-1520.

Román, José. "No olvidar: un filme documento". Apsi (15-28 octubre 1984), 46.

"Recuento de una década trágica". Hoy (9-15 octubre 1989), 10.

Sánchez, Manuel. Prólogo. ¿Dónde están? 4. Por el Arzobispado de Santiago. Vicaría de la Solidaridad. Santiago: Vicaría de la Solidaridad, 1979, 789-790.

Rojas, Juanita y Susana Kuncar. “¿Quién enterró el Informe Rettig?”. Análisis (13-19 mayo 1991), 20-25.

Subercaseaux, Bernardo. "Testimonio: una modalidad genérica de este tiempo". Pluma $y$ Pincel (febrero 1987), 48-49.

Verdugo, Patricia. Nota de la autora. Tiempo de días claros: los desaparecidos por Verdugo. Santiago: CESOC, Ediciones Chile América, 1990, 9.

Detenidos-desaparecidos: una herida abierta, $3^{\mathrm{a}}$ edición. Santiago: Editorial Aconcagua, 1986.

Weitzel, Ruby. Tumbas de cristal. Santiago: CESOC. Ediciones Chile América, 1991. 